\title{
A highly sensitive immunofluorometric assay for the measurement of aldosterone in small sample volumes: validation in mouse serum
}

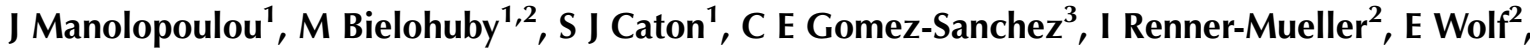 \\ U D Lichtenauer ${ }^{4}$, F Beuschlein ${ }^{1}$, A Hoeflich ${ }^{2,5}$ and M Bidlingmaier ${ }^{1}$ \\ ${ }^{1}$ Medizinische Klinik Innenstadt, Ludwig-Maximilians University, Ziemssenstr. 1, 80336 Munich, Germany \\ ${ }^{2}$ Institute of Molecular Animal Breeding and Biotechnology, LMU Munich 81377, Germany \\ ${ }^{3}$ Division of Endocrinology, GV Montgomery VA Medical Center and University of Mississippi Medical Center, Jackson, Mississippi 39216, USA \\ ${ }^{4}$ Institute for Molecular Medicine and Cell Research, University of Freiburg, Freiburg 79104, Germany \\ ${ }^{5}$ Laboratory of Mouse Genetics, Research Unit Genetics and Biometry, FBN Dummerstorf 18196, Germany \\ (Correspondence should be addressed to M Bidlingmaier; Email: martin.bidlingmaier@med.uni-muenchen.de)
}

\begin{abstract}
Data on the involvement of aldosterone in the regulation of the renin-angiotensin-aldosterone system (RAAS) in rodents are still scarce, partly due to the high sample volumes needed by commercially available assays and to the very low aldosterone concentrations present. We have developed a highly sensitive and non-isotopic immunoassay, requiring a volume of only $50 \mu \mathrm{l}$ serum for a duplicate measurement, employing a highly specific monoclonal antibody against aldosterone. The assay was validated in human and mouse samples and exhibited a linear working range from 10 to $1000 \mathrm{pg} / \mathrm{ml}$. Values obtained after a chromatographic purification step correlated significantly to the dichloromethane extraction ordinarily used. Basal aldosterone values were measured in 75 mouse hybrids and found within the linear range $(173 \pm 21 \mathrm{pg} / \mathrm{ml})$, with no significant difference between males and females. Additionally, we show an increase in
\end{abstract}

serum aldosterone in mice from 3 to 11 weeks of age. Mice of the same genetic background were treated with dexamethasone intraperitoneally $(n=7)$, resulting in significantly decreased concentrations $(35 \pm 3$ vs $114 \pm 33 \mathrm{pg} / \mathrm{ml}$ in controls; $P<0 \cdot 001)$. In contrast, adrenocorticotropic hormone resulted in significantly increased serum aldosterone $(603 \pm 119 \mathrm{pg} / \mathrm{ml}$; $n=7 ; P<0 \cdot 001)$, as did the physiological stimulation of the RAAS by a high $\mathrm{K}^{+} /$low $\mathrm{Na}^{+} \operatorname{diet}(1369 \pm 703$ vs $172 \pm 36 \mathrm{pg} / \mathrm{ml})$. In conclusion, we have developed and validated an extremely sensitive assay for determination of aldosterone concentrations from very small serum samples, which could be especially useful in pharmacological intervention studies in rodent models.

Journal of Endocrinology (2008) 196, 215-224

\section{Introduction}

An increasing body of work to examine adrenocortical zonation and to define factors involved in adrenal steroidogenesis has been performed in the rat model and other species (Peters et al. 1999, 2007, Takaya et al. 2001, Vinson 2003, 2004). However, genetically altered animal models which are of increasing importance for intervention studies and to establish a genotypephenotype relationship are restricted to the mouse (Peters et al. 1999, 2007, Berger et al. 2000, Takaya et al. 2001, Cole et al. 2003, Jensen et al. 2004, Vinson 2004, Kessler et al. 2005, Lee et al. 2005, Billet et al. 2006, Cao et al. 2006, Makhanova et al. 2006). Currently, there is a lack of longitudinal and systematic studies addressing adrenal gland growth and function as well as circulating aldosterone concentrations in mouse models. Plasma concentrations of corticosterone are relatively high and are therefore unproblematic to measure in mice (Weber et al. 1999, Coll et al. 2004, Wang et al. 2004, Karpac et al. 2005, Lee et al. 2005, Sausbier et al. 2005, Schmidt et al. 2006, Davies et al.

2007), whereas measurement of aldosterone can be problematic due to the low concentrations found in plasma and the limited amounts which can be collected from mice when repeated measurements must be carried out.

There is a discrepancy in the levels of aldosterone which have been reported so far in mice (Takaya et al. 2001, Cole et al. 2003, Cassis et al. 2005, Kessler et al. 2005, Cao et al. 2006, Makhanova et al. 2006). This problem arises from the variability in the assays commercially available for aldosterone measurement and the antibodies utilized. The antibodies used in commercial assays are mostly polyclonal and differ in affinity and specificity in recognizing aldosterone. Moreover, polyclonal antibodies against aldosterone are mostly incorporated in RIAs, but these require larger volumes and are associated with the obvious hazards and limitations of using radioactivity. In the present article, we present a non-isotopic, competitive immunoassay which utilizes a highly specific monoclonal antibody against aldosterone. The assay requires a small volume of serum or plasma which is especially desirable if an experimental procedure 
involves repeated in vivo sampling or if a variety of different parameters need to be determined. The assay is based on the competition principle with non-radioactive biotinylated aldosterone tracer in combination with streptavidin-europium for time-resolved fluorescence measurement (TR-FIA).

Studying the renin-angiotensin-aldosterone system (RAAS) in rodents has been hampered by the fact that the rodent adrenal gland is a complex organ with morphological differences found between species and strains, as well as at different ages; this poses obstacles in the assessment and comparison of data arising from transgenic and non-transgenic animal experiments. Mineralocorticoids are secreted by the outermost zone of the adrenal gland, the zona glomerulosa. The function of this zone is controlled both by the RAAS via angiotensin II and III (Williams 2005a) and by pituitary hormones, especially adrenocorticotropic hormone (ACTH; Seely et al. 1989, Muller 1995), but sodium chloride $(\mathrm{NaCl})$ and $\mathrm{K}^{+}$levels also play a major part (Lee et al. 2005, Williams 2005b).

In this study, we present a new assay to measure aldosterone and validate the assay by showing levels in three different mouse models: serum aldosterone in male and female mice at different ages, after stimulation and suppression of the hypothalamicpituitary-adrenal axis and after dietary intervention.

\section{Materials and Methods}

\section{Materials}

All solvents, reagents, and commercially available steroids were of analytical reagent grade or highest percent purity. Steroids, organic, and other materials were purchased from Fluka, Taufkirchen, Germany and Sigma-Aldrich. Streptavidin labeled with europium was purchased from Perkin-Elmer Life Sciences (Turku, Finland). Buffers were prepared in distilled deionized water.

\section{Anti-aldosterone antibody}

The monoclonal antibody against aldosterone used in the immunoassay was prepared as previously described (Gomez-Sanchez et al. 1987), where cross-reactivities for cortisol and corticosterone were found at $<0.003 \%$ and were at $<0 \cdot 1 \%$ for other potentially cross-reacting steroids. Crossreactivities for $5 \alpha$-dihydroaldosterone, $3 \alpha, 5 \alpha$-tetrahydroaldosterone, and other aldosterone metabolites have previously been reported at $<4 \%$ for this antibody (Abayasekara et al. 1993). The antibody was tested in our laboratory at a series of dilutions in sodium phosphate $\left(\mathrm{Na}_{2} \mathrm{HPO}_{4} \times 2 \mathrm{H}_{2} \mathrm{O}\right)$ buffer, $\mathrm{pH} 7 \cdot 4$, in order to determine the optimum concentration producing highest counts and highest displacement capability of the tracer used in the final assay procedure.

\section{Aldosterone tracer}

Biotinylated aldosterone, used as tracer in the immunoassay, was prepared by coupling aldosterone 3-O-carboxymethyloxime
(3-CMO) with a commercially available biotin hydrazide derivative according to a procedure previously described (Dressendorfer et al. 1992). Briefly, aldosterone 3-CMO active ester derivative was prepared on the first day as follows: $11.5 \mu \mathrm{mol}$ aldosterone 3-CMO (Steraloids Inc., Newport, RI, USA, no. Q2010-000) was dissolved in dry, amine-free $N, N$-dimethylformamide (DMF; Sigma, no. D8654) and coupled with $5.6 \mathrm{mg} N$-hydroxysuccinimide (NHS; Fluka, no. 56480) and $10.3 \mathrm{mg} N, N^{\prime}$-dicyclohexylcarbodiimide (DCC; Fluka, no. 36650). The reaction mixture was stored at room temperature under light exclusion for $24 \mathrm{~h}$. Coupling of the aldosterone-NHS ester to biotin was then carried out as follows: $25 \mu \mathrm{mol}$ biotinamidocaproyl hydrazide (Sigma, no. B3770), was dissolved in dimethyl sulfoxide (DMSO; Sigma, no. D5879), added to the initial reaction mixture and left at room temperature for another $24 \mathrm{~h}$ under light exclusion.

Aliquots of the aldosterone 3-CMO-biotin conjugate were further diluted in $50 \mathrm{mM}$ Tris- $\mathrm{HCl}$ buffer $(\mathrm{pH} \mathrm{7.8)}$ and applied to a reverse phase chromatography column for purification $(250 \times 4.6 \mathrm{~mm}$, Synergi $4 \mathrm{u}$ Fusion-RP 80A, Phenomenex, Aschaffenburg, Germany, no. 00G-4424-E0).

\section{Mice/experimental}

Mice (C57BL/6×NMRI) were maintained under specified pathogen-free conditions in a closed barrier system and monitored as recommended (Nicklas et al. 2002). All mice had free access to a standard rodent diet (V1534; Ssniff, Soest, Germany) and tap water ad libitum. The diet used contains a standard concentration of salts, a total of $0.24 \% \mathrm{Na}^{+}$and $0.91 \% \mathrm{~K}^{+}$. At an age of 3 weeks, animals were weaned and separated according to gender. At different time points $(3,5$, 7, 9, and 11 weeks after birth), male and female mice ( $n \geq 8$ / sex per age group) were weighed and then killed after obtaining a blood sample under ether anesthesia.

Blood samples were taken between 1300 and $1600 \mathrm{~h}$. The animals were anesthetized individually in a glass jar containing saturated ether vapor, and retro-orbital blood was collected with heparinized microcapillaries in clearly $<1 \mathrm{~min}$ from initial handling within the cage (Weber et al. 1999, Hoeflich et al. 2002). All animal experiments were carried out according to the German Animal Protection Law.

\section{Assay procedure}

Sample extraction The serum sample $(50 \mu \mathrm{l})$ collected from each animal was thawed and extracted using $2 \mathrm{ml}$ dichloromethane (DCM)/polyethylene glycol 10000 (PEG; $50 \mathrm{mg} / \mathrm{l}$ ) according to a modified version of that described earlier (Tschop et al. 1998). Each $50 \mu \mathrm{l}$ sample was pipetted in a glass tube and vortexed at a low speed for $30 \mathrm{~min}$ and after the two phases separated, the organic phase $(1.7 \mathrm{ml})$ was removed, transferred to another tube, and left to evaporate overnight. On the following day, samples were reconstituted with $10 \mu \mathrm{l}$ pure methanol and $190 \mu \mathrm{l}$ assay buffer. Values 
obtained upon measurement were multiplied by four to compensate for the dilution factor.

Assay procedure After reconstitution, $50 \mu \mathrm{l}$ of each of the samples were pipetted in duplicate directly onto microtiter plates previously coated with the monoclonal mouse anti-aldosterone capture antibody, along with aldosterone calibrators and controls. Calibrators were prepared from a $100 \%$ ethanolic stock of aldosterone at $10 \mathrm{mg} / \mathrm{ml}$ (Fluka 05521) by serial dilution in assay buffer so that calibrators contained $<5 \%$ ethanol. Subsequently, $100 \mu$ l biotinylated aldosterone tracer were pipetted into each well ( $5 \mathrm{pg} / \mathrm{well})$, the plate was sealed with self-adherent foil to avoid evaporation and incubated overnight at $4{ }^{\circ} \mathrm{C}$. The following day, the incubation was terminated by washing three times on an automatic microtiter plate washer (TECAN, SLT; Crailsheim, Germany) using an in-house prepared $0.05 \%$ v/v PBS/Tween-20 buffer. Two-hundred microliters per well of a streptavidin coupled to europium conjugate (PerkinElmer/Wallac) were then added and incubated for $30 \mathrm{~min}$ on a horizontal shaker at room temperature. After a sixfold wash of the plate, an in-house 'enhancement solution' was added and incubated on the shaker for $15 \mathrm{~min}$, used to transfer the europium conjugate into a fluorescent complex. The amount of biotinylated aldosterone bound was then measured using a fluorometer (VICTOR ${ }^{3}$, Perkin-Elmer).

\section{Chromatographic separation of aldosterone for use in immunoassay}

Comparison of aldosterone levels before and after chromatographic purification was carried out using partition chromatography with celite as the inert support (Celite 545 AW, SigmaAldrich) according to a modified version of the method described in Abraham et al. (1972) and used for comparison of chemiluminescence immunoassay in Materials and Methods in Schirpenbach et al. (2006). Briefly, the stationary phase consisted of $30 \%$ formamide in water, while the mobile phase consisted of a mixture of ethyl acetate in $n$-hexane with increasing polarity in a stepwise fashion. Aldosterone-containing fractions were eluted at $50 \%$ ethyl acetate: $n$-hexane. Eluates were dried under nitrogen gas pressure, and the dried residue on the walls of the glass tubes was re-dissolved in ethylene glycol water $(0 \cdot 2 \%)$ to a volume corresponding to the initial sample volume. Fifty-four plasma samples ( 34 mice and 20 human), covering the range from 0 to $1000 \mathrm{pg} / \mathrm{ml}$, were used for comparison of the celite chromatographic purification to the DCM extraction step included in our assay method.

\section{Plasma aldosterone in RIA compared with TR-FIA}

A series of 18 human plasma samples taken from daily profiles in two patients with Conn's syndrome were assayed for aldosterone content using a commercially available RIA kit (200 $\mu \mathrm{l}$ required per singlicate; Aldosterone Coat-A-Count, Diagnostics Product Corporation, Biermann, Germnay) and compared with the results obtained by the in-house TR-FIA
$(50 \mu \mathrm{l})$ after extraction with dichloromethane and reconstitution according to the aforementioned procedure.

TR-FIA validation All validation experiments carried out to assess the performance of the assay (see also Results section) were completed using human plasma samples which were extracted accordingly, due to the lack of ease of obtaining large volumes of serum or plasma from rodents.

\section{Stimulation/suppression tests}

Seven mice (aged 11 weeks) were injected intraperitoneally (i.p.) for 10 consecutive days with a daily dose of $250 \mu \mathrm{l}$ ACTH solution (Synacthen, Novartis, Nuremberg, Germany, $0.25 \mathrm{mg} / \mathrm{ml})$. A second group $(n=7)$ received daily i.p. injections of $200 \mu \mathrm{l}$ dexamethasone solution (Vetoquinol, Firma, Germany; $4 \mathrm{mg} / \mathrm{ml}$ ). A control group $(n=7)$ received $250 \mu \mathrm{l}$ vehicle only per day $(0.9 \% \mathrm{v} / \mathrm{v} \mathrm{NaCl}$; B Braun, Melsungen, Germany) intraperitoneally. On day 10, $3 \mathrm{~h}$ after the last injection, mice were killed, and the blood samples were collected in the afternoon as described above.

\section{Effect of an increased potassium diet on the adrenal RAAS}

Mice serum samples used for the assessment of aldosterone levels in mice given a high or low potassium containing diet were collected from the Institut furr Molekulare Medizin und Zellforschung, Universität, Freiburg. Seventeen, 12-week-old male wild-type mice (CD1), were divided into two groups and were fed for 5 weeks with a regular chow (total $\mathrm{Na}^{+}$and $\mathrm{K}^{+}$ made up 0.24 and $0.91 \%$ of the diet respectively) and distilled water in the control group $(n=10)$, and low sodium, high potassium chow (total $\mathrm{Na}^{+}$and $\mathrm{K}^{+}$at 0.014 and $1.14 \%$ of the diet respectively), and distilled water containing $2 \% \mathrm{v} / \mathrm{v} \mathrm{KCl}$ in the high potassium group $(n=7)$. Mice were anesthetized using isoflurane before decapitation and subsequently trunk blood was collected, and serum samples were transferred in aliquots to $1.5 \mathrm{ml}$ eppendorf tubes containing $10 \mu \mathrm{l}$ of $0.5 \mathrm{M}$ EDTA. Blood was spun down at $2000 \mathrm{~g}$ for $10 \mathrm{~min}$ at $4{ }^{\circ} \mathrm{C}$, and the supernatant (serum) was transferred to new $1.5 \mathrm{ml}$ eppendorfs. Samples were stored at $-20{ }^{\circ} \mathrm{C}$ until the time of assessment. Samples were measured using the TR-FIA assay with a $50 \mu \mathrm{l}$ sample using the Sample extraction and Assay procedure as described above, as well as with the DPC RIA using $400 \mu \mathrm{l}$ for the duplicate values.

\section{Statistical analysis}

Since the data presented did not meet the assumptions for parametric analysis, all data were analyzed using nonparametric tests. The relationship between the results obtained from chromatographic purification and dichloromethane extraction was analyzed using Pearson's correlation coefficient (one-tailed hypothesis). In order to examine differences in sex within each age group and overall Mann-Whitney $U$ test was performed. Kruskal-Wallis 
test was used to examine age-dependent differences in aldosterone levels in control mice and to examine differences in aldosterone levels between dexamethasone-treated, Synacthen-treated, and non-treated control mice. Significant differences in the multi-group test were specified by subsequent pair-wise post hoc Mann-Whitney $U$ tests.

\section{Results}

TR-FIA validation - performance of assay

Antibody titration The amount of aldosterone antibody immobilized on the microtiter plates was adjusted in order to give optimum sensitivity. Figure 1 shows the dilution curves, each representing the results obtained with decreasing amounts of antiserum. Although the estimated doses 50\% maximal binding, $\mathrm{ED}_{50}$, were very similar in the two upper curves, total counts decreased significantly at a 1:5000 titration so that 1:2500 was finally chosen as a compromise between the highest total counts and the lowest possible concentration of antiserum and was used in all following experiments. A typical standard curve for the aldosterone TR-FIA is shown in Fig. 2.

Analytical sensitivity The analytical sensitivity or lower limit of detection (LOD) of the assay was determined by assessing the zero standard in a typical assay a total of 20 times, and the mean $( \pm$ s.D.) value of the counts was calculated (50 $791 \pm 3444)$. A statistically significant difference from the zero standard was taken to be more than two times the standard deviation from this repeated mean (i.e., 43903 counts). The corresponding aldosterone value was thereafter determined from its intercept with the displacement curve and corresponded to $8 \mathrm{pg} / \mathrm{ml}$.

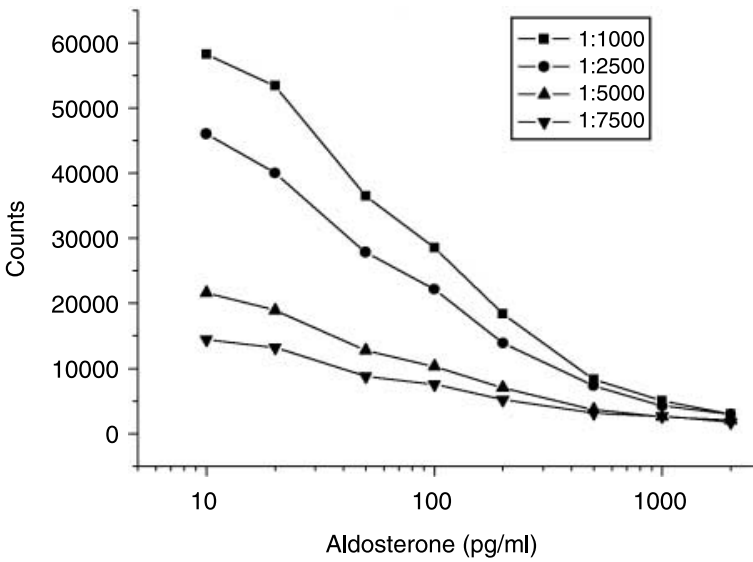

Figure 1 Curves for the displacement of aldosterone obtained by different titrations of anti-aldosterone antiserum used for coating of microtiter plates. The curves show counts at maximal binding when no unlabeled aldosterone is present in the calibrators and decreasing counts with reduced binding due to increasing concentrations of labeled aldosterone.

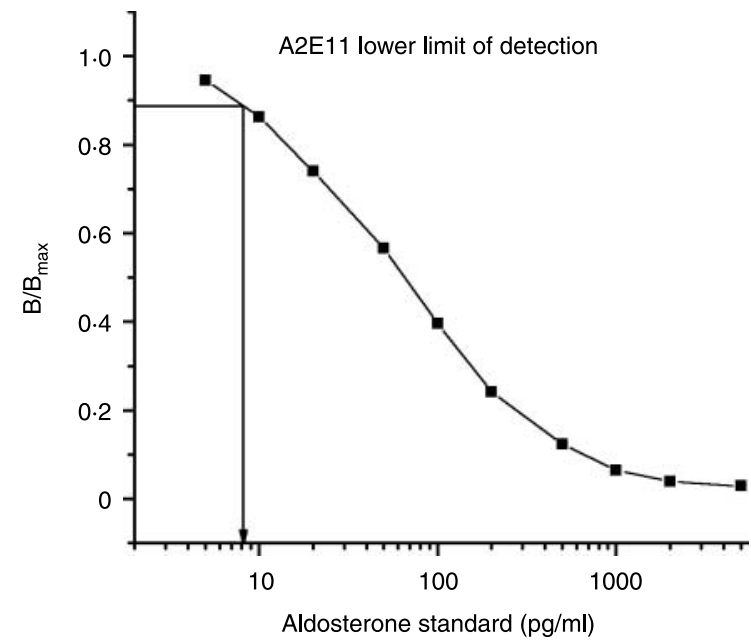

Figure 2 Binding of aldosterone in standards by monoclonal antibody for assay's displacement curve. Amount bound is expressed as a fraction of maximal binding in the standard containing no labeled aldosterone.

Precision Intra-assay coefficients of variation were determined by 20 -fold measurements of pooled plasma samples with aldosterone concentrations of 18,34 , and $139 \mathrm{pg} / \mathrm{ml}$ which were extracted, reconstituted, pooled again, and then added as samples on the same plate and found to be $7 \cdot 3,6 \cdot 3$, and $4 \cdot 4 \%$ respectively. Inter-assay coefficients of variation were determined by 20 -fold measurements, on consecutive days, of plasma samples of 14,37 , and $161 \mathrm{pg} / \mathrm{ml}$ and were found to be $15 \cdot 2,15 \cdot 1$, and $8 \cdot 0 \%$ respectively.

Linearity and recovery A plasma sample which was measured above the highest standard point of the linear range of the assay was diluted (1:2) in the matrix medium used to produce the calibrators and measured at $963 \mathrm{pg} / \mathrm{ml}$. This sample was then further serially diluted $(1: 4,1: 8,1: 16$, and $1: 32$ ), and the average recovery rate was found to be $105 \%$ (Table 1). Two plasma samples, measured at 29 and $20 \mathrm{pg} / \mathrm{ml}$, were each extracted and reconstituted a total of seven times

Table 1 Linearity of a plasma sample serially diluted in the ' 0 ' standard after extraction

\section{Dilution factor}

Dilution in 0 std

Original sample

$1: 2$

$1: 4$

$1: 8$

$1: 16$

$1: 32$

Avg \% expected 
and each of the standard points from 20 to $2000 \mathrm{pg} / \mathrm{ml}$ was then added at a 1:1 dilution to the sample. Average recovery for each sample was found at 99.9 and 106\% (Table 2).

\section{Clinical validation}

Plasma aldosterone in RIA compared with TR-FIA Plasma samples measured by the TR-FIA after extraction showed a high correlation to the values obtained by measurement with the commercially available RIA kit (Figs 3 and 4$)$ as described by the equation $\left(y=0.66 x-3 \cdot 69 ; R^{2}=\right.$ $0 \cdot 932)$. The TR-FIA values mirrored the fluctuations seen in the patients' aldosterone plasma levels throughout the day as measured by the RIA kit. The values measured by the in-house TR-FIA were at $\sim 66 \%$ of the concentration given by the RIA.

\section{Chromatographic separation of aldosterone for use in immunoassay}

A series of 40 samples were used to compare purification with the chromatographic technique to the extraction procedure utilizing dichloromethane, as described in Materials and Methods. Results obtained after celite partition chromatography $(x)$ in relation to those obtained after DCM extraction $(y)$ were highly correlated $(y=1 \cdot 2 x-3 \cdot 95$; $R^{2}=0 \cdot 96, P<0 \cdot 01$; Fig. 5).

\section{Serum aldosterone concentrations in male and female mice}

Values from all wild-type animals used in the study were examined in order to determine gender differences which may be present in mice. There was no overall significant difference $(P=0 \cdot 396)$ found between female $(n=35)$ and

Table 2 Recovery of two plasma samples, reconstituted after extraction and spiked at a 1:1 dilution with each of the standard points

\begin{tabular}{|c|c|c|c|}
\hline & $\begin{array}{c}\text { Measured } \\
\text { value }\end{array}$ & $\begin{array}{l}\text { Expected } \\
\text { value }\end{array}$ & $\begin{array}{l}\text { Expected } \\
\text { value }(\%)\end{array}$ \\
\hline \multicolumn{4}{|c|}{ 1:1 Dilution with std $(\mathrm{pg} / \mathrm{ml})$} \\
\hline Sample A & 29 & - & 100 \\
\hline+20 & 27 & $24 \cdot 5$ & $108 \cdot 6$ \\
\hline+50 & 46 & $39 \cdot 5$ & $115 \cdot 4$ \\
\hline+100 & 65 & $64 \cdot 5$ & $100 \cdot 3$ \\
\hline+200 & 119 & $114 \cdot 5$ & $103 \cdot 5$ \\
\hline+500 & 239 & $264 \cdot 5$ & $90 \cdot 4$ \\
\hline+1000 & 476 & $614 \cdot 5$ & $77 \cdot 5$ \\
\hline+2000 & 1053 & $1014 \cdot 5$ & $103 \cdot 8$ \\
\hline \multicolumn{3}{|l|}{ Avg \% expected } & $99 \cdot 9 \%$ \\
\hline Sample B & 20 & - & 100 \\
\hline+20 & 18 & 20 & 90 \\
\hline+50 & 42 & 35 & 120 \\
\hline+100 & 55 & 60 & $91 \cdot 6$ \\
\hline+200 & 120 & 110 & $109 \cdot 1$ \\
\hline+500 & 316 & 260 & $121 \cdot 5$ \\
\hline+1000 & 560 & 510 & $109 \cdot 8$ \\
\hline+2000 & 1011 & 1010 & $100 \cdot 1$ \\
\hline \multicolumn{3}{|l|}{ Avg \% expected } & $106 \%$ \\
\hline
\end{tabular}
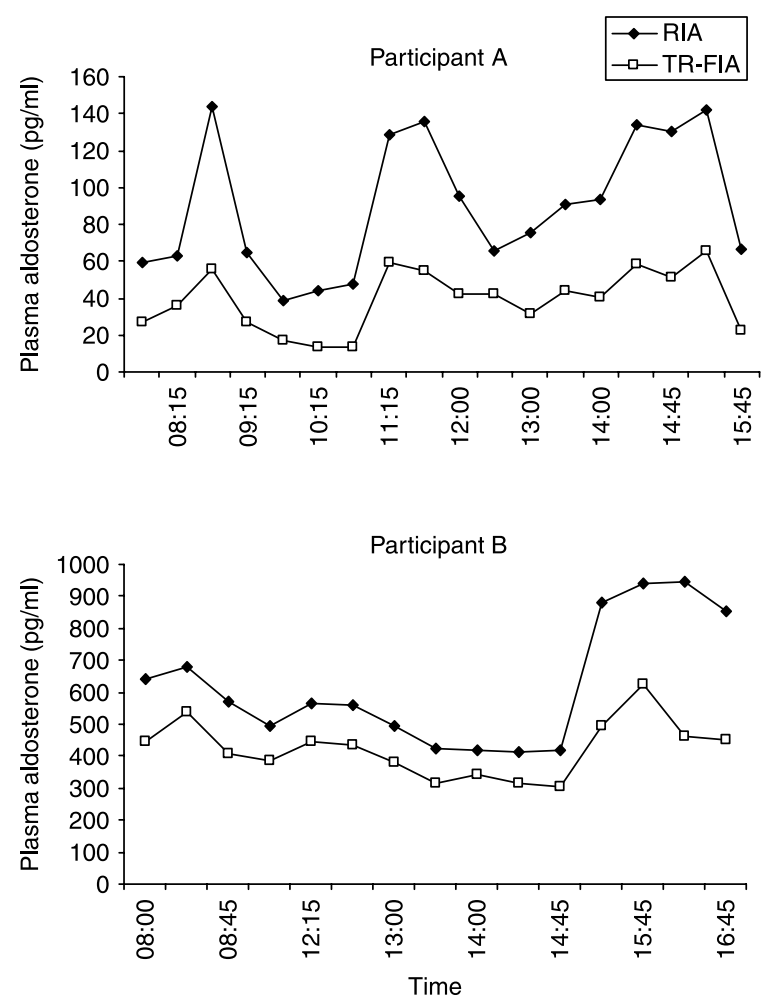

Figure 3 Comparison of plasma aldosterone as measured by the TR-FIA and by a commercially available RIA (DPC Coat-A-Count).

male $(n=40)$ mice, whose serum values had mean ( \pm s.E.M.) levels of $163 \pm 34$ and $181 \pm 27 \mathrm{pg} / \mathrm{ml}$ respectively (Fig. 6). In addition, there was no sex difference in any particular age group $(P>0 \cdot 05$ at $3,5,7,9$, and 11 weeks; Table 3$)$.

\section{Serum aldosterone levels during development}

Since no gender-dependent differences in serum aldosterone levels were observed throughout the studied points of time

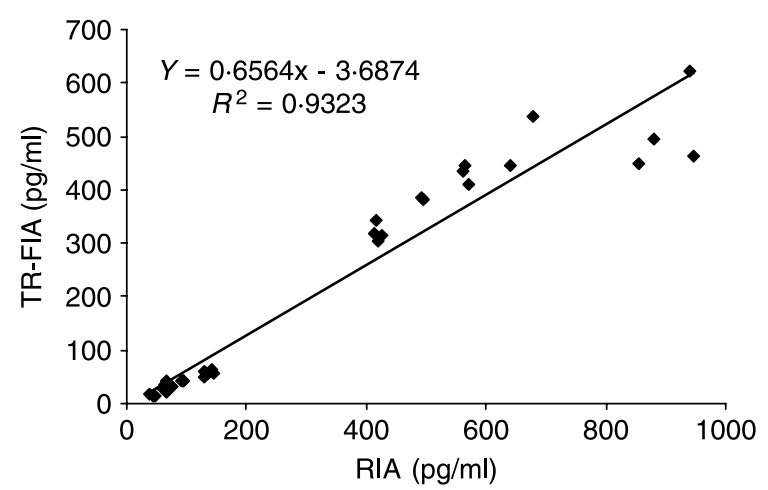

Figure 4 Correlation of plasma samples analyzed by both the commercial RIA and TR-FIA. The correlation was found to be extremely high $\left(R^{2}=0 \cdot 93\right)$ even at lower concentrations. TR-FIA measured at levels at $\sim 66 \%$ of the RIA. 


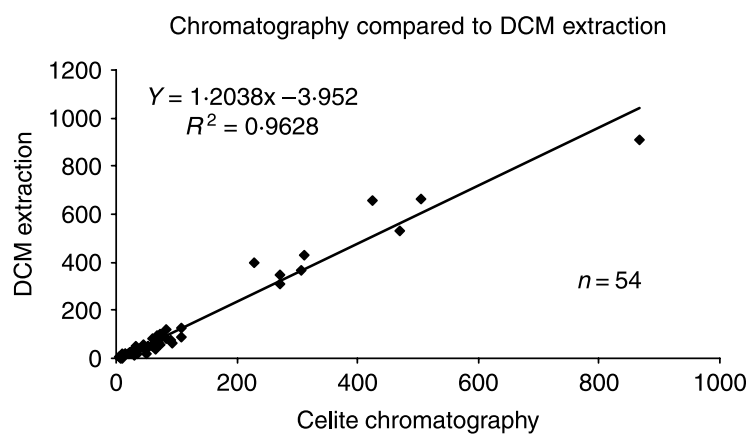

Figure 5 Correlation of aldosterone measurement in plasma samples as measured by the TR-FIA after partition chromatographic purification using celite as the inert support and a mixture of ethyl acetate/n-hexane as the mobile phase versus after an extraction procedure using dichloromethane/PEG 10000.

$(3,5,7,9$, and 11 weeks of age), aldosterone values for female and male mice were averaged at the different points of time (week 3, $n=8$; week 5, $n=8$; week 7, $n=27$; week 9, $n=12$; and week 11, $n=20$ ) and found to have mean ( \pm s.e.m.) aldosterone concentrations of $52 \pm 9,57 \pm 11,272 \pm 45$, $107 \pm 33$, and $174 \pm 34 \mathrm{pg} / \mathrm{ml}$ respectively (results for individual male and female age groups; Table 3 ). The Kruskal-Wallis non-parametric test displayed an overall significance between the groups $\left(\chi^{2}=1898 ; \mathrm{df}=4\right.$; $P=0 \cdot 001)$. No significant difference in aldosterone levels was found between weeks 3 and $5(P=0 \cdot 753)$. At an age of 7 weeks, aldosterone rose by $377 \%$ compared with the 5 -weekold mice $(P=0 \cdot 003)$. Although there was a drop at week 9, serum aldosterone concentrations remained high overall and were not significantly different between 9 and 11 weeks $(P=0 \cdot 115)$. At week 11, the aldosterone levels were still significantly higher than at both weeks 3 and $5(P=0.007$ and $P=0 \cdot 011)$.

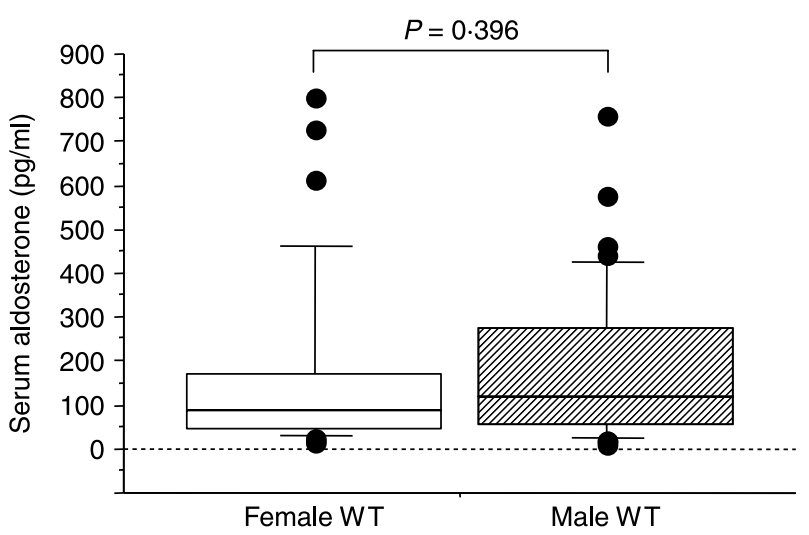

Figure 6 Mean serum aldosterone levels in female and male WT mice ( $n=35$ and $n=40$ respectively). Bars indicate 25th and 95th percentiles for each group, and significance was calculated by unpaired $t$-test.
Serum aldosterone during suppression and stimulation tests

The Kruskal-Wallis non-parametric test showed an overall significance between the three groups of control, dexamethasone suppressed, and ACTH-stimulated mice $\left(\chi^{2}=15 \cdot 866\right.$; $\mathrm{df}=2 ; P<0 \cdot 001$; Fig. 7). Animals treated with dexamethasone had significantly lower concentrations of aldosterone $(35 \pm 3 \mathrm{pg} / \mathrm{ml})$ than the control mice $(114 \pm 33 \mathrm{pg} / \mathrm{ml}$; $P=0 \cdot 021)$. Six out of the seven mice treated with dexamethasone suppression had values below the LOD $(8 \mathrm{pg} / \mathrm{ml})$. For the calculation of the mean, all these values were assigned a concentration of $8 \mathrm{pg} / \mathrm{ml}$. Mice stimulated with ACTH showed significantly elevated values compared with the control group $(603 \pm 119 \mathrm{pg} / \mathrm{ml} ; P=0 \cdot 003)$.

Effect of an increased potassium diet - stimulation/suppression of adrenal $R A A S$

Serum samples measured from mice sustained on a high $\mathrm{K}^{+} /$low $\mathrm{Na}^{+}$diet had mean aldosterone values of $1369 \pm 703 \mathrm{pg} / \mathrm{ml}$ and the control group had a mean of $172 \pm 36 \mathrm{pg} / \mathrm{ml}$, as measured by the in-house TR-FIA. The aldosterone values from the high $\mathrm{K}^{+}$/low $\mathrm{Na}^{+}$group were significantly higher than those of the control group $(P<0 \cdot 005$; Fig. 8). Similarly, the same samples from the same groups of mice when measured with the commercial DPC RIA kit gave values of $1744 \pm 697$ and $294 \pm 65 \mathrm{pg} / \mathrm{ml}$ in each respective group. Again, the high $\mathrm{K}^{+}$/ low $\mathrm{Na}^{+}$-fed animals were significantly higher compared with the controls $(P<0 \cdot 001)$. Results obtained from samples measured using the two different methods, RIA and TR-FIA, had no statistically significant difference when comparing any of the two groups of control and high potassium/low sodium diet.

\section{Discussion}

In the present study, we describe the development and application of an immunoassay designed to detect levels of aldosterone in small volumes of human or mouse serum or plasma samples. Due to the fact that aldosterone is the 'minority hormone' of the adrenal cortex, with plasma cortisol concentrations in humans up to 2000 times higher than plasma aldosterone concentrations (Muller 1995), its assessment is often tricky and inconsistency exists in the levels reported so far.

Assays previously developed for the measurement of aldosterone in human serum or plasma and modified for use in animals, are mostly radioactive, require high volumes and employ polyclonal antisera. Though several aldosterone assays have been described in the literature so far, two studies report the use of a monoclonal antibody (de Lauzon et al. 1987, Hanquez et al. 1988). These either required large $2 \mathrm{ml}$ samples for extraction purposes and were not validated in serum of rodents, as in the case of the first assay, or as in the second, application of the assay using biological fluids was only suggested and not demonstrated or applied. However, 
Table 3 Serum aldosterone concentrations in female and male mice at increasing weeks of age

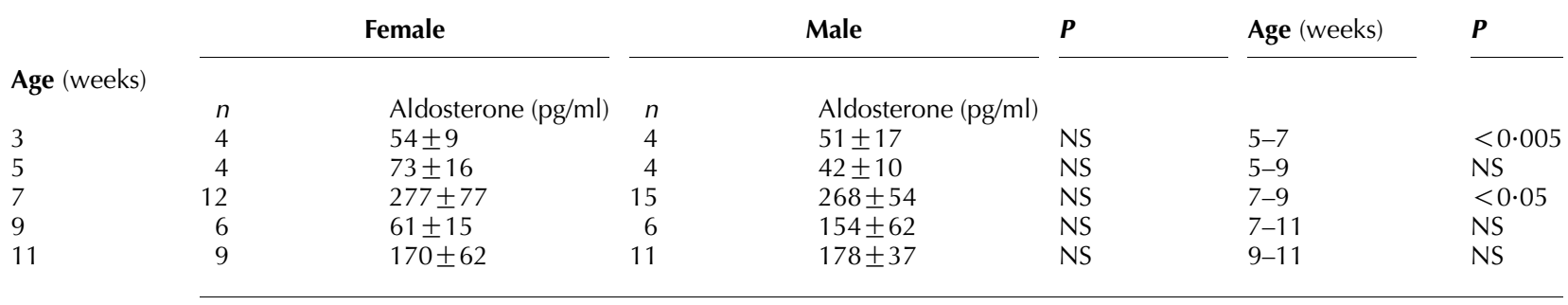

There was no significant difference between the male and female mice throughout the weeks of development.

other more sensitive RIAs, either direct or requiring extraction, have also been reported requiring smaller volumes and having lower limits of detection up to $2 \mathrm{pg} / \mathrm{ml}$ (Nussberger et al. 1984, Miller et al. 1997).

\section{Assay validation}

In the assay described and validated here, we utilize a monoclonal antibody which allows the measurement of concentrations in a very sensitive range and with reproducible results. The assay works in a competitive manner with the advantage of incorporating a non-isotopic, biotin-labeled aldosterone tracer, so that the amount of aldosterone present in the sample correlates inversely with the amount of antibody immobilized in each well and bound to the biotin tracer. Although the exact amount of immobilized aldosterone per well is unknown, the results from the dilution curves in Fig. 1 indicated that the optimum amount of antiserum was that yielded by a well-coating at a 1:2500 titration of the original supernatant retrieved from cell culture. The validation criteria for the assay have been met accordingly, and the assay shows good linearity and reproducibility

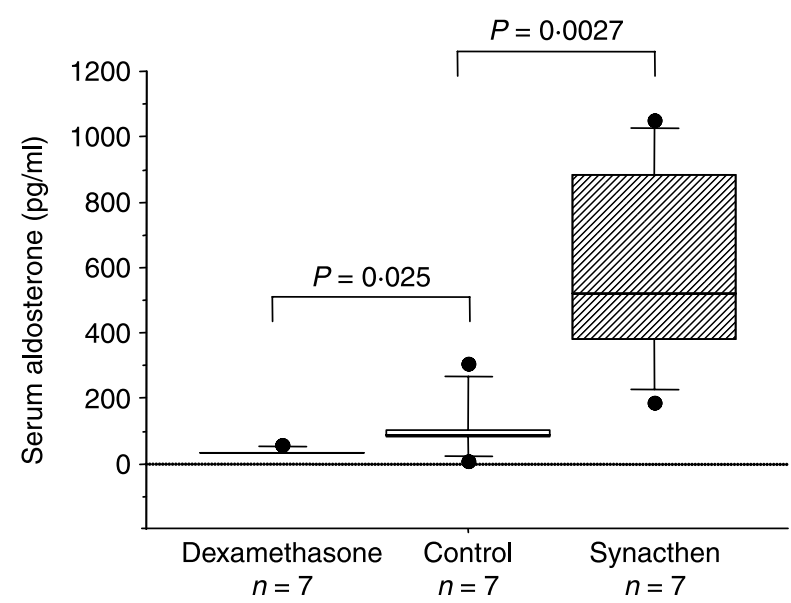

Figure 7 Mean serum aldosterone levels in grouped male and female WT mice treated with dexamethasone for 10 days, $\mathrm{NaCl}$ (control group) for 10 days, and Synacthen ACTH for 10 days. Significance compared with baseline control group was determined by unpaired $t$-test. following extraction of samples with dichloromethane. The main advantage presented here is the very small amount of only $50 \mu \mathrm{l}$ serum or plasma necessary for a duplicate measurement due to modification of a previously established extraction procedure. This is especially useful for procedures requiring repeated blood drawing, for example, that recovered by tail-vein bleeding. Furthermore, the assay allows detection of aldosterone levels at low concentrations as may be the case in pharmacological studies or in genetically modified mice in which circulating aldosterone concentrations are altered and may be extremely low.

As a further step towards validating the assay, we have correlated the values obtained with the TR-FIA to a commercially available RIA commonly used in many laboratories carrying out animal studies, albeit with conflicting results, for baseline values in wild-type rodent plasma and serum samples. Although our TR-FIA measures at a lower level than that of the RIA, possibly due to the fact that a monoclonal antibody is more selective in the species of aldosterone within a sample that it recognizes, there was good

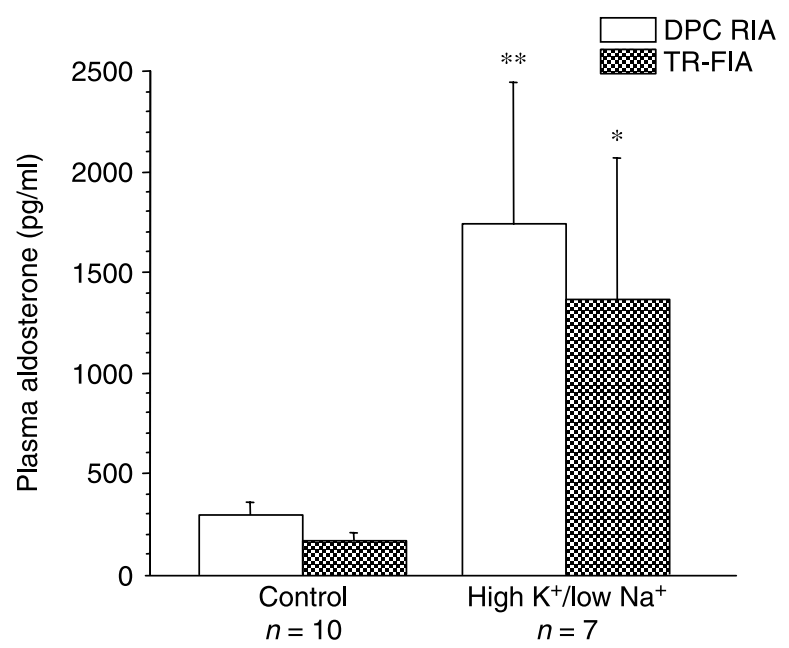

Figure 8 Plasma aldosterone levels as measured by the TR-FIA (grey bars) and by the DPC RIA (white bars), in two groups of mice sustained on a standard chow diet and a high potassium $\left(\mathrm{K}^{+}\right)$diet for 5 weeks. ${ }^{*} P<0 \cdot 005$ and ${ }^{* *} P<0.001$ significant difference of the high potassium diet group as compared with controls when measured by respective assay. 
correlation between the two assays $\left(R^{2}=0 \cdot 93\right.$; Figs 3 and 4$)$. The difference in measurement can also be explained by the fact that the commercial RIA we used for comparison does not incorporate an extraction or chromatographic purification step in the assay procedure, a step which excludes the possibility of potentially interfering substances giving falsely high results. Differences in the specificity of antibodies as well as several other factors may contribute, one important issue arising from the difference in calibration of assays which often generates higher values in some compared with lower values in others. Major differences in mean aldosterone values despite high inter-assay correlations are common and have previously been described (Schirpenbach et al. 2006). It was our finding that the DPC kit systematically measures samples $\sim 30 \%$ higher than the assay developed here. Other authors have also reported in the past that, in patients with chronic renal failure, this direct method overestimates aldosterone levels by $\sim 37 \%$ (Miller et al. 1997). The lack of agreement between aldosterone assays, especially those without an extraction step, which has recently been highlighted (Stowasser \& Gordon 2006), of course may have serious implications in a clinical setting.

\section{Gender- and age-related differences in serum aldosterone concentrations of mice}

In the present study, we report values for serum aldosterone in mice which are well within the measurable range of this assay. After assessment of samples taken from 75 C57BL/6 XNMRI mice we found no gender-dependent difference. This observation included male and female mice aged between 3 and 11 weeks after birth. We exclude the possibility that anesthesia or blood sampling may have influenced steroid levels in our experiments since, as has previously been shown (Vahl et al. 2005), rapid sampling carried out in $<3$ min does not trigger a stress response. To our knowledge so far, there has been no in-depth study describing gender-related levels of aldosterone in these or any other strain of mice. In one recent study (Sausbier et al. 2005), carried out to evaluate the influence of large conductance, voltage- and $\mathrm{Ca}^{2+}$-dependent $\mathrm{K}^{+}(\mathrm{BK})$ channels, BK mutant mice exhibited higher serum aldosterone levels than wild-type mice of the same SV129 $\times$ C57BL/ 6 genetic background, but no differences between male and female mice were observed in either group.

Other authors have previously found (Zhang et al. 2003, Jensen et al. 2004), that aldosterone does not change significantly in rodents during postnatal development, however, these experiments were carried out in rats. The importance of aldosterone in developmental processes, such as growth of the kidney, has been addressed by many studies. For instance, targeted disruption of aldosterone and the components of the RAAS in mice lead to diminished kidney growth, vascular wall thickening, and low blood pressure (Jensen et al. 2004). In the present investigation, we observed a highly significant increase in the levels of aldosterone between 5 and 7 weeks of age and, though these levels decreased at week 9, levels recovered at week 11 and were not statistically significant compared with week 7 . It is possible that blood samples, particularly in female mice around 7 weeks of age, have been taken in a 'sensitive phase', for example, during proestrus, as influences of the cycle stage have been shown to affect steroid hormone concentrations (Atkinson \& Waddell 1997). However, we see a similar longitudinal pattern of the aldosterone concentrations also in male mice and believe that this was a physiological increase in both genders. These data are supported by a current study where we have also analyzed the zonal composition in the adrenal glands of exactly the same strain of mice (Bielohuby et al. 2007). Although total cortical volume was clearly higher in female mice when compared with their male littermates, the zona glomerulosa did not contribute to this genderdependent phenotype. These findings confirm our measurements on aldosterone concentrations comparing male and female mice. We also found a significant rise of total zona glomerulosa volume comparing 3 and 7 weeks of age with no further significant changes until week 11, similar to what we observed in serum aldosterone concentrations. Changes in aldosterone levels accompanied by changes in adrenal weights have not been systematically studied yet and these observations merit further attention.

No difference in plasma aldosterone concentrations between neonate and adult 3-month-old mice (C57BL/6 strain) was reported by Cao et al. (2006). As we did not include mice older than 11 weeks in our study, it is possible that the aldosterone levels decline thereafter. In another study showing aldosterone levels in 1-week- and 1-month-old wild-type and proopiomelanocortin (POMC) null animals, the authors reported levels which were approximately twice as high in the wild types at 1 month compared with 1 week $(793 \pm 103$ vs $357 \pm 145 \mathrm{pg} / \mathrm{ml})$ and significantly decreased at 1 month $(203 \pm 39 \mathrm{pg} / \mathrm{ml})$ in the POMC null mice, while no difference occurred between wild-type and mutant mice at week 1 ( $89 \pm 5$ pg/ml; Karpac et al. 2005). However, the different strain, assay, and blood sampling techniques used hamper a comparison between the studies.

\section{Aldosterone and $A C T H$ in mice}

Research on the actions of ACTH on the adrenal cortex has focused, so far, mainly on its maintenance of glucocorticoids in plasma, for example, its role in aiding steroidogenesis via transfer of cholesterol across the mitochondria in conjunction with steroid acute regulatory protein (StAR). Its chronic effects to enhance the gland's steroidogenic enzymes in the biosynthetic pathway and to make more cells capable of conducting steroidogenesis have also been studied (Vinson 2003). Although assessment of adrenal function in human patients for diagnostic purposes is carried out by standardized ACTH tests (Alia et al. 2006), there is little direct evidence available for the actions of ACTH on the production of aldosterone in rodents. Aldosterone has primarily been studied in the context of its function within the RAAS. One study has 
shown diminished, though detectable, levels of aldosterone with no distinguishable architecture of the zona glomerulosa in POMC-deficient mice (Coll et al. 2004) and the authors in that study report that aldosterone levels do not increase in response to ACTH injection. Other researchers report aldosterone levels below limits of detection in mice with a complete lack of ACTH (Yaswen et al. 1999), which illustrates the need for standardization in order to avoid discrepancies in assay measurement as an interfering factor. It was our purpose to indicate the applicability and relevance of the current assay by showing that adrenocortical function can be monitored effectively in small sample volumes. To demonstrate this, we carried out a study including pharmacological intervention with dexamethasone suppression as well as stimulation with an ACTH analog (Synacthen). ACTH is thought to be an acute regulator of aldosterone synthesis in stress situations (Muller 1995, Davies et al. 2007). To demonstrate that there were clear increases and decreases in the production of aldosterone under the circumstances of the study and to make sure that there was definite hyper- and hypoplasia of the adrenal gland under stimulation and suppression we used a previously established protocol (Coll et al. 2006).

\section{Increased potassium diet and the adrenal RAAS}

Elevated extracellular potassium concentrations directly stimulate aldosterone production by acting on the steroidogenic pathways occurring in the cells of the zona glomerulosa (Muller 1995, Williams 2005a). In our assessment of serum samples from mice administered a high $\mathrm{K}^{+}$diet for 5 weeks, aldosterone levels were greatly increased as expected. The extent of the increase was confirmed as results were in extremely close correlation with a commercial assay requiring a much larger sample volume. The findings of aldosterone levels in wild-type mice on a normal potassium diet are in agreement with the findings of previous authors $(172 \pm 36$ vs $201 \cdot 8 \pm 26 \cdot 2 \mathrm{pg} / \mathrm{ml}$; Arrighi et al. 2001), however, the concentrations after a high $\mathrm{K}^{+}$diet are significantly lower, though this may be expected as the mice in that study were only given high $\mathrm{K}^{+}$chow without concurrently increased amounts of $\mathrm{K}^{+}$in the drinking water, and the diet was only given for 2 weeks as opposed to 5 weeks as was the case in our study.

\section{Conclusion}

In the present article, we describe the development of a highly sensitive TR-FIA for the determination of aldosterone levels in small volumes of serum or plasma. The assay employs a highly specific monoclonal antibody against aldosterone and requires a sample of only $50 \mu \mathrm{l}$. We have validated the system in human plasma and mouse serum samples and shown its potential to be used in pharmacological and dietary intervention studies, and to monitor the regulation of the RAAS. Furthermore, we have shown that in mice there is an increase in aldosterone levels around puberty. As mice aged between 3 and 11 weeks are frequently used to carry out studies, our results may serve as a reference point for aldosterone concentrations in future experiments. We have thus shown that the assay presented is a reliable technique which can potentially be used to measure the mineralocorticoid aldosterone in a variety of experimental settings and mouse models where endocrine changes are being investigated.

\section{Acknowledgements}

We are especially thankful to P Renner and T Mittmann for excellent animal care. This study was funded in part by the German DFG-Research Training Unit 1029. There is no conflict of interest that would prejudice the impartiality of this funding.

\section{References}

Abayasekara DRE, Onyezili NI, Whitehouse BJ, Laird SM \& Vinson GP 1993 Effects of chronic corticotrophin treatment on aldosterone metabolism in the rat. Journal of Endocrinology 137 445-455.

Abraham GE, Buster JE, Lucas LA, Corrales PC \& Teller RC 1972 Chromatographic separation of steroid hormones for use in immunoassay. Analytical Letters 5 509-517.

Alia P, Villabona C, Gimenez O, Sospedra E, Soler J \& Navarro MA 2006 Profile, mean residence time of ACTH and cortisol responses after low and standard ACTH tests in healthy volunteers. Clinical Endocrinology 65 346-351.

Arrighi I, Bloch-Faure M, Grahammer F, Bleich M, Warth R, Mengual R, Drici MD, Barhanin J \& Meneton P 2001 Altered potassium balance and aldosterone secretion in a mouse model of human congenital long QT syndrome. PNAS 98 8792-8797.

Atkinson HC \& Waddell BJ 1997 Circadian variation in basal plasma corticosterone and adrenocorticotropin in the rat: sexual dimorphism and changes across the estrous cycle. Endocrinology 138 3842-3848.

Berger S, Bleich M, Schmid W, Greger R \& Schutz G 2000 Mineralocorticoid receptor knockout mice: lessons on $\mathrm{Na}+$ metabolism. Kidney International 57 1295-1298.

Bielohuby M, Herbach N, Wanke R, Maser-Gluth C, Beuschlein F, Wolf E \& Hoeflich A 2007 Growth analysis of the mouse adrenal gland from weaning to adulthood: time- and gender-dependent alterations of cell size and number in the cortical compartment. American Journal of Physiology. Endocrinology and Metabolism 293 E139-E146.

Billet S, Bardin S, Tacine R, Clauser E \& Conchon S 2006 The AT1A receptor 'gain-of-function' mutant N111S/delta329 is both constitutively active and hyperreactive to angiotensin II. American Journal of Physiology. Endocrinology and Metabolism 290 E840-E848.

Cao XR, Shi PP, Sigmund RD, Husted RF, Sigmund CD, Williamson RA, Stokes JB \& Yang B 2006 Mice heterozygous for beta-ENaC deletion have defective potassium excretion. American Journal of Physiology. Renal Physiology 291 F107-F115.

Cassis LA, Helton MJ, Howatt DA, King VL \& Daugherty A 2005 Aldosterone does not mediate angiotensin II-induced atherosclerosis and abdominal aortic aneurysms. British Journal of Pharmacology 144 443-448.

Cole JM, Khokhlova N, Sutliff RL, Adams JW, Disher KM, Zhao H, Capecchi MR, Corvol P \& Bernstein KE 2003 Mice lacking endothelial ACE: normal blood pressure with elevated angiotensin II. Hypertension 41 313-321.

Coll AP, Challis BG, Yeo GS, Snell K, Piper SJ, Halsall D, Thresher RR \& O'Rahilly S 2004 The effects of proopiomelanocortin deficiency on murine adrenal development and responsiveness to adrenocorticotropin. Endocrinology 145 4721-4727. 
Coll AP, Fassnacht M, Klammer S, Hahner S, Schulte DM, Piper S, Tung YC, Challis BG, Weinstein Y, Allolio B et al. 2006 Peripheral administration of the N-terminal pro-opiomelanocortin fragment $1-28$ to Pomc-/ - mice reduces food intake and weight but does not affect adrenal growth or corticosterone production. Journal of Endocrinology 190 515-525.

Davies E, Omer S, Buckingham JC, Morris JF \& Christian HC 2007 Expression and externalization of annexin 1 in the adrenal gland: structure and function of the adrenal gland in annexin 1-null mutant mice. Endocrinology 148 1030-1038.

Dressendorfer RA, Kirschbaum C, Rohde W, Stahl F \& Strasburger CJ 1992 Synthesis of a cortisol-biotin conjugate and evaluation as a tracer in an immunoassay for salivary cortisol measurement. Journal of Steroid Biochemistry 43 683-692.

Gomez-Sanchez CE, Foecking MF, Ferris MW, Chavarri MR, Uribe L \& Gomez-Sanchez EP 1987 The production of monoclonal antibodies against aldosterone. Steroids 49 581-587.

Hanquez C, Rajkowski KM, Desfosses B \& Cittanova N 1988 A competitive microtitre plate enzyme immunoassay for plasma aldosterone using a monoclonal antibody. Journal of Steroid Biochemistry 31 939-945.

Hoeflich A, Weber MM, Fisch T, Nedbal S, Fottner C, Elmlinger MW, Wanke R \& Wolf E 2002 Insulin-like growth factor binding protein 2 (IGFBP-2) separates hypertrophic and hyperplastic effects of growth hormone (GH)/IGF-I excess on adrenocortical cells in vivo. FASEB Journal 16 1721-1731.

Jensen BL, Stubbe J, Madsen K, Nielsen FT \& Skott O 2004 The reninangiotensin system in kidney development: role of COX-2 and adrenal steroids. Acta Physiologica Scandinavica 181 549-559.

Karpac J, Ostwald D, Bui S, Hunnewell P, Shankar M \& Hochgeschwender U 2005 Development, maintenance, and function of the adrenal gland in early postnatal proopiomelanocortin-null mutant mice. Endocrinology 146 2555-2562.

Kessler SP, Hashimoto S, Senanayake PS, Gaughan C, Sen GC \& Schnermann J 2005 Nephron function in transgenic mice with selective vascular or tubular expression of angiotensin-converting enzyme. Journal of the American Society of Nephrology 16 3535-3542.

de Lauzon S, Le Trang N, Moreau MF, Gentin M, Christeff N, Desfosses B \& Cittanova M 1987 Murine monoclonal antibody against aldosterone: production, characterization and use for enzymoimmunoassay. Journal of Steroid Biochemistry 28 459-463.

Lee G, Makhanova N, Caron K, Lopez ML, Gomez RA, Smithies O \& Kim HS 2005 Homeostatic responses in the adrenal cortex to the absence of aldosterone in mice. Endocrinology 146 2650-2656.

Makhanova N, Sequeira-Lopez ML, Gomez RA, Kim HS \& Smithies O 2006 Disturbed homeostasis in sodium-restricted mice heterozygous and homozygous for aldosterone synthase gene disruption. Hypertension 48 1151-1159.

Miller MA, Sagnella GA \& MacGregor GA 1997 Extraction method and nonextracted kit method compared for measuring plasma aldosterone. Clinical Chemistry 43 1995-1997.

Muller J 1995 Aldosterone: the minority hormone of the adrenal cortex. Steroids $602-9$

Nicklas W, Baneux P, Boot R, Decelle T, Deeny AA, Fumanelli M \& IllgenWilcke B 2002 Recommendations for the health monitoring of rodent and rabbit colonies in breeding and experimental units. Laboratory Animals 36 20-42.

Nussberger J, Waeber B, Brunner HR, Burris JF \& Vetter W 1984 Highly sensitive microassay for aldosterone in unextracted plasma: comparison with two other methods. Journal of Laboratory and Clinical Medicine 104 789-796.

Peters J, Obermuller N, Woyth A, Peters B, Maser-Gluth C, Kranzlin B \& Gretz N 1999 Losartan and angiotensin II inhibit aldosterone production in anephric rats via different actions on the intraadrenal renin-angiotensin system. Endocrinology 140 675-682.

Peters B, Teubner P, Clausmeyer S, Puschner T, Maser-Gluth C, Wrede HJ, Kranzlin B \& Peters J 2007 StAR expression and the long-term aldosterone response to high-potassium diet in Wistar-Kyoto and spontaneously hypertensive rats. American Journal of Physiology. Endocrinology and Metabolism 292 E16-E23.

Sausbier M, Arntz C, Bucurenciu I, Zhao H, Zhou XB, Sausbier U, Feil S, Kamm S, Essin K, Sailer CA et al. 2005 Elevated blood pressure linked to primary hyperaldosteronism and impaired vasodilation in BK channeldeficient mice. Circulation 112 60-68.

Schirpenbach C, Seiler L, Maser-Gluth C, Beuschlein F, Reincke M \& Bidlingmaier M 2006 Automated chemiluminescence-immunoassay for aldosterone during dynamic testing: comparison to radioimmunoassays with and without extraction steps. Clinical Chemistry 52 1749-1755.

Schmidt MV, Levine S, Alam S, Harbich D, Sterlemann V, Ganea K, de Kloet ER, Holsboer F \& Muller MB 2006 Metabolic signals modulate hypothalamicpituitary-adrenal axis activation during maternal separation of the neonatal mouse. Journal of Neuroendocrinology 18 865-874.

Seely EW, Conlin PR, Brent GA \& Dluhy RG 1989 Adrenocorticotropin stimulation of aldosterone: prolonged continuous versus pulsatile infusion. Journal of Clinical Endocrinology and Metabolism 69 1028-1032.

Stowasser M \& Gordon RD 2006 Monogenic mineralocorticoid hypertension. Best Practice and Research Clinical Endocrinology and Metabolism 20 401-420.

Takaya J, Matsusaka T, Katori H, Tamura M, Miyazaki Y, Homma T \& Ichikawa I 2001 In situ demonstration of angiotensin-dependent and independent pathways for hyperaldosteronism during chronic extracellular fluid volume depletion. Molecular Endocrinology 15 2229-2235.

Tschop M, Behre HM, Nieschlag E, Dressendorfer RA \& Strasburger CJ 1998 A time-resolved fluorescence immunoassay for the measurement of testosterone in saliva: monitoring of testosterone replacement therapy with testosterone buciclate. Clinical Chemistry and Laboratory Medicine 36 223-230.

Vahl TP, Ulrich-Lai YM, Ostrander MM, Dolgas CM, Elfers EE, Seeley RJ, D'Alessio DA \& Herman JP 2005 Comparative analysis of ACTH and corticosterone sampling methods in rats. American Journal of Physiology. Endocrinology and Metabolism 289 E823-E828.

Vinson GP 2003 Adrenocortical zonation and ACTH. Microscopy Research and Technique 61 227-239.

Vinson GP 2004 Glomerulosa function and aldosterone synthesis in the rat. Molecular and Cellular Endocrinology 217 59-65.

Wang Q, Clement S, Gabbiani G, Horisberger JD, Burnier M, Rossier BC \& Hummler E 2004 Chronic hyperaldosteronism in a transgenic mouse model fails to induce cardiac remodeling and fibrosis under a normal-salt diet. American Journal of Physiology. Renal Physiology 286 F1178-F1184.

Weber MM, Fottner C, Schmidt P, Brodowski KM, Gittner K, Lahm H, Engelhardt D \& Wolf E 1999 Postnatal overexpression of insulin-like growth factor II in transgenic mice is associated with adrenocortical hyperplasia and enhanced steroidogenesis. Endocrinology 140 1537-1543.

Williams GH 2005a Aldosterone biosynthesis, regulation, and classical mechanism of action. Heart Failure Reviews 10 7-13.

Williams GH 2005b Cardiovascular benefits of aldosterone receptor antagonists: what about potassium? Hypertension 46 265-266.

Yaswen L, Diehl N, Brennan MB \& Hochgeschwender U 1999 Obesity in the mouse model of pro-opiomelanocortin deficiency responds to peripheral melanocortin. Nature Medicine 5 1066-1070.

Zhang MZ, Wang SW, Cheng H, Zhang Y, McKanna JA \& Harris RC 2003 Regulation of renal cortical cyclooxygenase-2 in young rats. American Journal of Physiology. Renal Physiology 285 F881-F888.

\section{Received in final form 18 October 2007 Accepted 2 November 2007 Made available online as an Accepted Preprint 2 November 2007}

